\title{
THE
}

\section{Cultural Contradictions of the Anytime, Anywhere Economy: Reframing Communication Technology}

\author{
Nikhilesh Dholakia \\ University of Rhode Island, nik@uri.edu \\ Detlev Zwick \\ dzwick@schulich.yorku.ca
}

Follow this and additional works at: https://digitalcommons.uri.edu/cba_facpubs

Part of the E-Commerce Commons, Marketing Commons, Other Business Commons, and the Other Philosophy Commons

Terms of Use

All rights reserved under copyright.

\section{Citation/Publisher Attribution}

Dholakia, Nikhilesh, and Detlev Zwick. "Cultural Contradictions of the Anytime, Anywhere Economy: Reframing Communication Technology." Telematics and Informatics, vol. 21, no. 2 (May 2004): 123-141. DOI: 10.1016/S0736-5853(03)00052-2

This Article is brought to you for free and open access by the College of Business at DigitalCommons@URI. It has been accepted for inclusion in College of Business Faculty Publications by an authorized administrator of DigitalCommons@URI. For more information, please contact digitalcommons-group@uri.edu. 


\author{
Nikhilesh Dholakia, University of Rhode Island, USA \\ Detlev Zwick, York University, Canada \\ Email contact: nik@uri.edu
}

Acknowledgements: The authors are grateful to Dr. Ruby Roy Dholakia and the reviewers of Telematics \&Informatics for comments on earlier drafts of this paper.

Published in: Telematics and Informatics, 2004, vol. 21(2), 123-141.

\title{
Draft date: February 2, 2003
}

\section{Cultural Contradictions of the Anytime, Anywhere Economy: Reframing Communication Technology}

\section{ABSTRACT}

Technology-aided ubiquity and instantaneity have emerged as major goals of most information technology providers and of certain classes of users such as "road warriors". New mobile technologies have genie-in-a-bottle type near-magical qualities: these technologies promise anytime, anywhere access to information and services. While the complex science, systems, and economics of such technologies receive considerable attention from industry executives and researchers, the social and cultural aspects of these technologies attract less attention. This paper explores the oft-contradictory promises and pitfalls of anytime, anywhere technologies from a cultural standpoint. It makes suggestions for reinterpreting these technologies for greater human good.

Keywords: Mobile, Communications, Culture, Digital Divide, Networks

\section{Introduction}

With the rapid spread of mobile communications, companies in the information and communication technology (ICT) fields are promising the world at our fingertips: anything, anywhere, anytime, for any reason, and through any media. Consider, for example, some of the scenarios for the fourth-generation $(4 \mathrm{G})$ mobile communications:

ß..there will be a number of devices hooked up on the Net. From very small, voice only cell-phones, to larger cell- 
phones with data capability, to Communicator size dataphones, to PDAs with larger screens to lap-tops with wireless access. Cars will come with built-in wireless access....the voice-only device will shrink into a (speech controlled?) earphone with a short range bluetooth link to some wireless device you carry around. Gadgets and clothes will be wireless enabled, and we will see goggles with built-in projection of a full-size screen (Lind 2001).

ß...a vision of the Wireless World is the emerging need to bridge the real and the personal virtual world and to continuously stay in contact with both. The Wireless World therefore has to address communications amongst things, humans and cymans (our synthetic counterparts in the virtual cyber-world ... sort of autonomous avatars). As such, a Wireless World of the future will become our natural enhanced living environment (WWRF 2002).

ß.. 4G could be the combination of different types of Wireless Personal Area Networks (WPANs), Wireless Local Area Networks (WLANs) and a 3G cellular system such as UMTS...[with] seamless integration of the different systems in the network ... [using] low cost, low power consumption, multi-mode (i.e. adaptive to different air interfaces), multi-band radio terminals (Eriksson 2002).

Their creators claim that there are genie-in-a-bottle type near-magical qualities in these technologies that promise individual freedom, creativity, performance, and empowerment through anytime-anywhere access to information and services. The complex science, systems, and economics of such technologies receive considerable attention from industry executives, journalists, and researchers (see, for example, McGrath 2000). The non-instrumental and noneconomic aspects, however, attract less attention; particularly the cultural contradictions and social implications that arise as several stakeholders - manufacturers, designers, marketers, application developers, and users - negotiate the meaning of mobile communication technologies.

We want to formulate an extension to the technological view by introducing a social and cultural perspective to the debate. Two theoretical frameworks - the Social Construction of Technology (SCOT) theory (Kline \& Pinch, 1996; Pinch \& Bijker, 1984)and the Mediation of 
Technology (MOT) theory(Mackay \& Gillespie, 1992; Rutsky, 1993, 1999)form the conceptual basis upon which we will build our response to the dominant view of technological determinism. We will briefly elaborate on these theories below but in a nutshell, such theories presume that the technological artifact only exists through our descriptions and practices. This is not an ontological claim. We recognize, of course, the physical existence of artifacts. What SCOT and MOT are referring to is their constitution as meaningful objects through acts of configuration, mediation, and active interpretation by social actors. As such, the technological is thoroughly intertwined with the social (Grint \& Woolgar, 1995; Latour \& Woolgar, 1979).

Therefore, to recognize the multifaceted, polysemic, and contradictory nature of technology we need to move beyond an analysis of anytime-anywhere communications as merely a set of technological specifications and capabilities. We suggest instead to turn our attention to the discursive and interpretive work employed by stakeholders involved in the development, marketing, and consumption of mobile technologies. Such a strategy enables us to a) illustrate the cultural and social contradictions of anytime-anywhere technologies, and b) outline alternative paths to constructing the meaning of mobile technologies, which is ultimately a political act that seeks to mobilize, as it were, mobile technologies as an agent of global equality.

The rest of this paper has four parts. First, we explain the basic premises of the SCOT and MOT theories. Second, we apply these theories to the artifact at hand, mobile communication technologies, and introduce three key contradictions that characterize the current interpretive 
flexibility of mobile technologies. Third, we outline how within our theoretical framework, current attempts by some social actors to "fix" the meaning of the emerging technologies of ubiquity and instantaneity could be resisted and alternative interpretations may be advanced. Fourth and finally, some concluding remarks are offered.

\section{SCOT and MOT: Basic Concepts}

The Social Construction of Technology (SCOT) theory was developed in reaction to a deterministic view of the evolution, design, and consumption of technology. Its proponents believe that the process of developing and consuming a technology happens not along a linear but a multi-directional path. That is, until the final technological solution to a problem is developed, an alternation of variation and selection occurs that takes into account not only technological capabilities but social, cultural, and political discourses. $[1]$

The strength then of the SCOT approach is that it takes into consideration the importance of various "relevant social groups" (RSGs) within a particular field of technological and scientific development in flexibly interpreting a new technology up until the stage where closure occurs. Closure can be described as the moment at which the collectivity of RSGs (e.g., manufacturers, designers, marketers, policymakers, users) reaches a consensus about the meaning of the technology. In other words, the question for SCOT theorists is: how does the controversy around the technology stabilizes or crystallizes into a particular form? Or to put it another way: how a particular artifact came to be perceived as "the mobile communication device", whilst other options were abandoned. Accordingly, SCOT theory is based on a three-stage model (Rosen, 1993): 1) interpretive flexibility, where there are still multiple interpretations possible of what the artifact actually is, 2) stabilization, where social mechanisms (media debates, 
advertising, demonstration, usage, accidents, etc.) bring about closure of this multiplicity of interpretations, and 3) the wider context, where the closure mechanisms are being linked to their wider social-cultural milieu. In its strict form, the key to the social construction of technology is the number, nature, and power of RSGs engaged in the process (Godin, 1997; Grint \& Woolgar, 1995).

Mediation of Technology (MOT) theory is related yet distinct from SCOT. The MOT approach can be seen as an attempt to link (or mediate) the sphere of production (i.e., the conception and design of an artifact) with the sphere of consumption (i.e., the consumption practices). In an attempt to extend and systematize what they call the "usual Social Shaping of Technology" approach (similar to what we call SCOT), Mackay and Gillespie (1992) argue that, for an analysis of technology, three different spheres must be treated as analytically distinct: 1) the conception and development on the producer side during which a functional and symbolical encoding of the technology, be it intentional or not, takes place, 2) the marketing of the technology, and 3) the appropriation by users. The mediation takes place somewhere along the path from production to consumption of the technology by a mass market. Mediators could be trade fairs, the media, stores, designers, peers, sales personnel, and experts. Marketing and advertising arguably play the most important role as mediators, especially for mass-marketed consumer products.

The MOT theory is important in at least two ways. First, it opens up some of the conceptual rigidity of the SCOT model because of its closeness to the semiotic tradition. While SCOT rejects technological determinism by introducing the concept of interpretive flexibility, this 
approach nonetheless claims that interpretive stability of the meaning of a particular technology can and will be reached, which establishes the second stage. The MOT approach rejects this rigidity of total interpretive stability and instead suggests that even as some RSGs may converge on the same meaning for a certain technology, not all will. Hence there will always be a multitude of interpretations of what the technology stands for (see also Godin, 1997; Kline, 2000). In addition, every consensus may always become the object for later contestation by new groups or members of the original consensus (Kline \& Pinch, 1996). MOT thus proclaims a more persistent negotiation of meanings and the simultaneous existence of different interpretations (polysemy of technology). Second, and very importantly for our purposes, the MOT theory suggests that the mediation of technology is particularly important when several RSGs perceive of a technology very differently (see also Rutsky, 1993). In sum, SCOT and MOT together propose that the meaning or the nature of a technology is not a function of the technical characteristics inherent in the technology. Instead, the nature, form, and capacities of a technology are the upshot of various antecedent circumstances - in particular the design, manufacturing, and marketing activities - involved in the development of the technology, as well as the interpretive negotiation of a number of RSGs leading to socially constituted consensuses about the technology's meaning (Grint \& Woolgar, 1995). As such, a technology is not determined by what it does but by what it means to a social group at a particular point in time. This anti-deterministic theoretical approach, it should be obvious, is radically different from technological determinism because it opens up the technological artifact as a site for interpretive construction, and, even more importantly, deconstruction of existing meanings.

In the next section, we apply these theories to mobile communication technologies and show how mediators are attempting to create interpretive stability around this technology, and yet 
contradictions persist that perpetuate the current interpretive flexibility of mobile technologies. 3) Freedom, Creativity, Empowerment: Moving from Interpretive Flexibility to Stability

Mobile communication technologies are still at a very early stage of development. Like the rest of the edifice of the New Economy, the "mobile future" is built on a foundation of promises. According to SCOT/MOT, promises issued by interested RSGs - in most cases device manufacturers, application providers, or network operators - are to be seen as rhetorical tools to funnel the attention of other RSGs such as business customers, end users, and policy makers into a certain interpretive direction. As Pinch and Bijker (1984, p. 426) point out, "[C]losure in technology involves the stabilization of an artifact and the 'disappearance' of problems. To close a technological 'controversy' the problems need not be solved in the common sense of the word. The key point is whether the RSGs see the problem as being solved." Mediators, most notably high-tech advertisers and the popular media, do the job of making a controversy disappear and reaching interpretive stability of mobile technologies in general. More important, however, is what precedes these attempts to accomplish what SCOT theorists call rhetorical closure. This is the social construction of the problem itself. Until now, the formulation of the problems that new communication technologies need to address have almost entirely emanated from the powerful cultural, economic, and technological core of Western Europe and North America, resulting in a focus on individual consumption and worker/business productivity.

\section{3a) Constructing a Field of Problems}

Businesses are certainly chief producer of technological promises as solutions for consumer problems, but popular cultural 
representations also play an important role in the shaping of consumption practices and consumer expectations. (du Gay, 1997; Lury, 1996; Schroeder, 2002) Historically, our understanding of technology was grounded on the double imperative of rationality and instrumentality (Heidegger, 1977; Huyssen, 1986). Fictional accounts - especially science fiction books, movies, and TV shows - extend such imperatives to a fascination with gadgets that combine functionality and stylishness. Such futuristic imagery also, however, channels corporate imaginations into grandiose directions and away from larger, pragmatic, grounded, and global visions for mobile technologies.

Text Box: Figure 1: Some Relevant Social Groups, Problems, and Solutions in the Construction of Mobile Communication Technologies(Authors' interpretation based on Pinch and Bijker (1984). Note: To conserve space, not all RSGs, problems, and solutions are shown.) 
The range of user benefits promised by the developers and marketers of new mobile technologies begins to mimic the ideal of the tech-savvy, autonomous (male) protagonist of the 
science fiction narrative. Two main themes (problems) of mobile technologies $[2]$ are constructed marketing, sales, and advertising experts, by protagonist RSGs, who become the mediators between developers and manufacturers at the production end and consumer groups:

1) the omni-powerful consumer and 2) the ultra-productive worker. These interpretations of the technology are challenged by two other themes: 3) privacy, and 4) worker surveillance (see Figure 1).

Figure 1 thus shows how initially there is a high degree of interpretive flexibility associated with new mobile communication technologies. This perspective helps represent the "seamless web" of meaning-creating and-constructing actors (Hughes, 1986)who compete to install contesting meanings of the same artifact. It should be obvious that such an interpretive openness creates possibilities for multi-directional technology developments based on social consensus, not on simple technological feasibility, as the uniform message coming from the market mediators, mainly advertising, would have us believe (Mackay \& Gillespie, 1992).

There are still too many RSGs vying with each other and throwing their voices in the mix. Interpretive stability in the sense of rhetorical closure has not yet been achieved in the case of mobile technologies and several user and other relevant groups still have the power to alter the direction of the technological development. Specifically, as three key cultural contradictions persist and intensify with the further development and spread of anytime-anywhere technology, rhetorical closure, the second stage of the social construction of this technology, may remain difficult. 
According to the MOT perspective, much of what prevents a rhetorical closure of mobile communication technology has to do with the artifact's polysemic nature. It is because of this polysemy that mediation between production and consumption becomes necessary. Hence, marketing and advertising aim at "fixing" the artifact's meaning; or, if that is still too far ahead, these mediating entities at least try to limit the range of possible interpretations. In essence, then, the act of mediation is the attempt of removing competing or even contradictory meanings from the social and discursive construction of technology, even as it is acknowledged that a complete stability cannot be reached. We argue that the current interpretive instability of anywhere-anytime technologies originates mainly from three(Robins \& Webster, 1999, p. 101)cultural contradictions (see Table 1):

\section{Table 1: Three Spheres of Contradiction of Mobile ICTs}

\begin{tabular}{|l|l|l|}
\hline Sphere of Contradiction & Dominant View & Contesting View \\
\hline Individual & Empowering & Threatening \\
\hline Social & Liberating & Confining \\
\hline Global & Equalizing power & Further dividing power \\
\hline
\end{tabular}

1.Mobile ICTs allow for instant and ubiquitous access to information on one hand and a nearcomplete loss of privacy on the other.

The irony with all new information and communication technologies (including the formation of massive databases, the Internet, or mobile communication) is that with every improvement in regards to data storage, accessibility, manipulation, and exchange, the individual user of these ICTs becomes simultaneously a more powerful subject of the networked society and the Internet galaxy(Castells, 2001)and a more wanted, valued, and targeted object of data miners. The mobile communication network, like other data networks before it, appears therefore simultaneously empowering and threatening.

2.Mobile ICTs promote unprecedented work productivity and convenient consumption experiences on one hand and an increasing inability to separate work time from leisure time on the other.

A major impact of new information technologies has been the interpenetration of lifespaces: work life and home life blend into each other, shaking up and transforming fundamental social relations that currently make up our social organization. People increasingly lead a parallel 
existence on an electronic plane where the separation between home and work is no more than that between different folders in the storage media of their computing devices. For mobile technology firms, people who blur the home/work boundaries with their mobile technology gadgets and services are the prime targets. They represent the companies' larger fantasy of a "cybernetic market place" (Robins \& Webster, 1999, p. 101)and the fantasy of society as a highly mobile producing and consuming high-tech machine. To put it in Habermasian terms, mobile technologies colonize every aspect of people's lifeworld even as the same technologies bear for many the promise of less time spent at work. The technology confines even as it seems liberating.

3.Mobile ICTs provide great global coverage of mobile communications on one hand and growing disparities in service levels and accessibility on the other.

Mobile communication networks as well as adoption of digitally enabled mobile phones have been growing fastest in some of the poorest nations in the world (Dholakia and Kshetri 2001). Large transnational corporations and allied global players are active drivers in the extension of global communication networks and the proliferation of mobile communication devices (Castells, 2001). Yet, while their workforce even in the most remote locations finds itself increasingly wired into global flows of communication with "always on" modes and anytimeanywhere accessibility (of information and of own labor power), the majority of citizens in these locales remain "wired out". As we will discuss in more length below, as long as accessibility to mobile communication is tied to ownership of mobile devices, we will witness intensification of this contradiction. 
In sum, cultural contradictions are being constructed and perpetuated by mobile communication technologies. It is perhaps wrong to say that these contradictions of anywhereanytime technologies are "inherent" in the artifact itself $[3]$. Yet, there can be no doubt that various RSGs interpret this technology differently. The contradictory nature and the persisting interpretive flexibility that we detect cannot be easily discerned within "technological" frameworks of analysis because they downplay the important role of social actors in shaping the technology at hand in the first place (MacKenzie \& Wajcman, 1985).

The focus of traditional perspectives on mobile communication technologies is unfortunately limited to technological specifications and performance aspects, which invariably leads down the path to the dominant but one-sided perception of the technology (see the middle column in Table 1). The problem with these "technologically determinist" approaches is that they look at the dominant and finally stabilized view of technology as the only possible outcome of technological development. Analysts in this tradition ignore the semiotic work that mediators such as marketers and advertisers do to construct and then naturalize the dominant interpretation in an effort to develop a rhetoric closure, frequently against more or less powerful contesting interpretations and perceptions (the right-side column in Table 1). Therefore, unlike SCOT and MOT, determinist accounts conceal the hermeneutic character of the artifact and ignore its original (and some would argue, ongoing) polysemy. 
Our charge is more than a scholastic exercise over the ontology of technology. Accepting that a technology is socially constructed and not the natural, linear outcome of, say, the straightforward application of basic scientific knowledge as often claimed by engineers, designers, and scientists (Latour, 1987; Latour \& Woolgar, 1979), means accepting that technological development can be contested, negotiated, and changed. We believe that this theoretical opening can lead to policy decisions that might emphasize socially and ethically sensitive aspects of anytime-anywhere technologies, such as the emphasis of accessibility over ownership. In the next section, we give an example of a nascent, yet instructive, initiative that aims at socially (re)constructing mobile technologies as a driver for global social and economic equality.

\section{Connectedness in a Divided World}

There is a long tradition of prophesying that the advent of advanced ICTs will bring the solution to all our social ills (see, for example, Gates et al., 1995). But as the stories of the telegraph, the radio, the television, the personal computer, and most recently the Internet lay bare, ICTs introduce as many new social ills as they presumably cure (Castells, 2001; Nye, 1997; Webster, 1995). To be sure, technologies can promote global participatory business communities, improved communication flows, cultural self-expression, and social justice but optimistic visions of a magical global communications matrix alone will not get us there (Drucker, 1970, 1985; Robins \& Webster, 1999). Therefore, we suggest some concrete measures particularly for corporate players that might help socially construct mobile communication technologies in ways that go beyond the desire to make a profit and (also) aim 
at ameliorating the current technological inequality. We would advocate an interpretation of the artifact away from a tool that enhances individual consumerism and competitive work relationships to an avenue that may

Text Box: Figure 2: The Transformational Challenge for Mobile Technologies

finally make true of the promise of an equal and truly democratized global communication network.

To understand the new mobile technologies in a global context, we have to bear in mind that technology-aided connectivity is a privilege of the minority. While it is true that some advanced nations such as Finland have near-universal mobile connectivity, for most of the world this is not the case. The preexisting "industrial divide" of the past couple of centuries 
now has a new overlay of the "digital divide" (Gruenwald 2001). Juxtaposing the widening digital divide and the rapid diffusion of mobile technologies, some interesting observations can be made.

While the digital divide between rich and poor countries in terms of PCs connected to the Internet remains very wide, there is evidence to suggest that mobile technologies are finding rapid acceptance in the developing world, potentially narrowing the gap between rich and poor: -In the late 1990s, mobile phones in the poorest nations of the world grew at a rate 2.5 times that in the richest nations, and these phones were more likely to be digital-ready than in any category of advanced nations (Dholakia and Kshetri 2001).

-In the developing nations, access to digital communications is often through shared media rather than through individually owned media. This is not only true for PC-based access (through Internet cafes, for example) but also in the case of mobile phones. For example, in Bangladesh, Grameen Telecom has a goal of having a shared, rentable mobile phone in every village (Gruenwald 2001).

-The business models of providing digital access are quite different from the business models of promoting ownership of digital media and individual subscription to digital services. "The moment you separate ownership from access, the opportunities are huge," according to C. K. Prahalad of University of Michigan (quoted in Gruenwald 2001).

The transformational challenge for the developers and marketers of mobile technologies is to bring about major changes in both the central themes (the social and discursive construction of problems) as well as the primary solutions of mobile technologies (see Figure 2). The theme of "individual empowerment" is fine for the advanced, elite segments of the global market but technologies featuring such a theme will not revolutionize the everyday life of most people in the world. Similarly, the goal of "digital ownership" - of rendering people into technologyladen versions of the cartoon character "Inspector Gadget" - may appeal to select segments of 
"road warriors" but is not relevant to the mass of humanity. By shifting to more ameliorative themes (including the quest for true autonomy, not gadget-induced illusion of omnipresence), and to the simpler goal of access rather than ownership, new mobile technologies could have the potential to revolutionize the everyday life of vast segments of people in the world. The challenge is to liberate the new technologies from the matrix of techno-frenzy (Virilio 2000) and to transform them into tools for humanity.

The challenge of transforming mobile technologies in fundamental ways sounds appealing, but is it realistic? After all, the ultimate goal of technology developers and marketers is the "bottom line" (Palen, 2002). High-tech firms have even more myopic goals and strategies now than earlier because technology-induced ubiquity and instantaneity have convulsive impacts on the global financial markets. It is no accident that organizations most involved in bringing the Internet and mobile communication capabilities to developing countries are not commercial firms but two nonprofit organizations: World Bank and the United Nations (Thyfault, 2001). For the commercial ICT firms, visionary transformation and re-interpretation of the problems and solutions of mobile technologies make sense only if they are cost-neutral and preferably profitable.

\section{4a) Some Promising Initiatives}


Text Box: Box 1: HP's World e-Inclusion Program HP's “world e-Inclusion” business strategy seeks to broaden access to the social and economic opportunities in developing countries - markets that are traditionally excluded from strategic considerations. The focus is on sustainable business ventures that benefit the rural poor in Africa, Asia, Central and Eastern Europe, and Latin America. Some of the key principles underlying this strategy are summarized below: e-Inclusion PrincipleExplanationIllustrationFocus on people, not technologyTechnology must operate in conjunction with business, economic, political, and social systems. Technology providers need to get close to the new potential customers, partners, employees and inventors in the developing world to seek or invent local solutions.HP's strategic cooperation with the Foundation for Sustainable Development of Costa Rica to develop and implement telecenters for villages in remote areas without traditional infrastructure. Housed in recycled shipping containers, these Little Intelligent Communities (LINCOS) are satellite-operated, solarpowered, and equipped with HP hardware and high-speed Internet connections.Develop strong global and local partnershipsHP cannot do it alone. Others can bring knowledge, experience, and skills that are critical to discovering new business approaches, cultivating markets, and growing profitable revenue streams for the long-term.In Senegal, HP partnered with Joko Inc. to develop community technology centers in lowincome urban and rural areas to develop and sell an array of e-services. The local communities identified their needs such as computer training, e-mail, word processing, access to credit, information about crops and pricing, or selling handicrafts on-line.Projects should be sustainableIf external sources of support are removed, the project should be able to support itself and continue. Grameen project in Bangladesh is developing village self-sustaining telecenters with an initial focus on telemedicine and the efficient transfer of funds, especially for individuals and small businesses. Source: http://www.hp.com/e-inclusion/

\section{Some technology companies have started the process of reinterpreting the role of technology in contexts that are more global than the "road warrior" segments of advanced nations. One of the pioneers in this regard is Hewlett-Packard (see Box 1).}


The primacy of access over ownership also drives efforts of other global technology players.

Lucent Technologies and eBay combined forces to install computers and the Internet - initially via cell phones - in a small school outside Guatemala City. The next step in this technology aid program is the setting up of a community telecenter that will provide the villagers with education and training via satellite access to the Internet (Thyfault, 2001). Cost-neutrality is assured via usage fees from tourists checking E-mail. Microsoft contributed money, hardware, and software to fund community-based projects that offer education, employment training, and disaster relief to developing countries. Cisco Systems has committed to extending its educational Cisco Networking Academy program to 24 of the world's countries ranked as leastdeveloped by the United Nations (Thyfault, 2001). While HP and others are attempting to promote a grand and global vision, this is not the only approach for reinterpreting and reorienting new mobile technologies.

\section{4b) Suggested New Metrics for Assessing ICTs}

In fact, technology firms can achieve good results by applying some simple metrics throughout the development and marketing cycle. In what follows, we propose some suggestive metrics that new technology developers and strategists can employ, grouped into "autonomy," "creativity," and "amelioration" categories. These metrics produce, as it were, a sort of roadmap for various RSGs to construct a "problem and solution" set that produces new interpretive avenues for the technology.

\section{4b-1) Autonomy Metrics}

-Will this technology help the users set their own agendas and schedules?

- Can users control electronic access by others into my space without offending or alienating them?

-Will this technology help users to work in ways that they like to work in, without feeling 
corporate pressures for goal-focused productivity?

-Will this technology help users to consume in ways that they like to consume, without feeling like a constant target of corporate marketing efforts?

\section{4b-2) Creativity Metrics}

-Can users make this technology function in ways that they want (and not merely imparting the ability to choose various ring tones)?

-Can users (re)design and mold this technology according to their wishes?

- Can this technology help users express themselves in ways that are not programmed and patterned?

\section{4b-3) Bridging and Amelioration Metrics}

-Does this technology provide the possibility of low-cost access without the need for substantial private expenditures on gadgets and services?

-Does this technology offer access equally, regardless of income, race, gender, education, climate, geography, etc.?

- Can this technology provide income and a competitive edge to those who find their products and services in a situation of declining global demand?

-Does this technology have the ability to improve human development factors such as health and literacy?

-Does this technology promote and support social and political justice (and help people to counter social and political oppression)?

While the "bridging and amelioration" category is social in nature and relevant mainly to the disadvantaged masses on the indigent side of the digital divide, the "autonomy" and "creativity" metrics are individual in nature and are relevant to technology users all over the world, including the gadget-rich road warriors. The "winning combinations" that could really boost the "bottom line" of technology firms are those that combine and blend all metrics.

\section{Concluding Remarks}

The technological juggernaut of providing mobile connectivity on a global basis has started 
rolling. In the next few years, it will bring about massive changes in the ways people live and work. The new mobile technologies are infused richly with promises of ubiquity and instantaneity, which in turn promise a world of unimagined individual freedom, wealth, and social connections. The realities of such technologies are often at odds with their promises. The social and cultural contradictions of new mobile technologies of ubiquity and instantaneity can be summarized under these three headings:

-Individual Level: The technologies of ubiquity and instantaneity promise unbounded empowerment and self-actualization. Thus they appear to be benign conditions of human existence but could (and often do) transmogrify into threatening, quasi-totalitarian, panoptic conditions of existence (Dholakia and Zwick 2001).

-Social Level: The technologies of ubiquity and instantaneity promise liberation from life's complexities but often result in inescapable dependencies, interpenetration, and implication of hitherto separate lifeworlds. Social relations are being transformed and with them what we regard as fundamental structures of our social organization. As users "jack in" complex matrices of patterned consumption and Chaplinesque ( la "Modern Times") cycles of production, the social may turn into an empty theater of consumption, a fantasy of society as a highly mobile producing and consuming high-tech machine (Firat and Dholakia, 1998; Robins \& Webster, 1999, p. 101).

- Global Level: The technologies of ubiquity and instantaneity promise a world of borderless connectivity that would bridge the chasm that we call the "global digital divide," but there are few incentives for technology firms or government agencies to connect up the masses of digitally excluded humanity. Instead of actualizing the equalizing power of mobile technologies, they are continuously cast and constituted in a way that perpetuates global inequality.

These contradictions are strong and serious, but they are not intractable. Some corporations are attacking them through visionary strategies. A lot more could be done in terms of overcoming such contradictions if new individualistic and social metrics are employed during the design and marketing cycles of the new mobile technologies. 
The SCOT/MOT approach allows us to recast the "question concerning mobile technology."

With the SCOT/MOT perspectives, we are no longer locked into technological evolution that is linear, over-determined, and channeled into a singular path, out of people's hands and simply driven by the magical forces of science and money. In fact, SCOT/MOT approaches allow the constitution of mobile technology as the outcome of a complex process of negotiation, interpretation, and the construction of truth, which, if Foucault is correct, is closely tied to a struggle over power. This theoretical approach provides us with ways to contest, resist, and reinterpret the dominant meaning of technology and to suggest new and hopefully improved ones. Ultimately, we opened up a theoretical terrain from which a constructive and multilayered critique of mobile technologies could be launched.

\section{5a) Agenda for Future Research}

In this paper, we have illustrated alternative interpretations and directions of mobile ICTs, drawing on the SCOT/MOT approaches. Using such approaches opens up new agendas for further research. In particular, we would like to sketch out the following possible directions for future work:

1) The rhetorical critique: We contend that the developers and promoters of mobile technologies have mobilized a language of desire and imagination that is both limited and limiting in terms of the technology's larger promises. Promoters of mobile technologies employ storylines that are reminiscent of classic science fiction: the imagination of new worlds, technology as somehow alive, and the human (presumably white, male) protagonist in control of his own technological destiny. It becomes readily apparent that such strategies 
not only ignore the "dark" side of these new technologies but also may not resonate with markets outside Europe and North America. In developing countries, immediate, concrete, and affordable solutions to communication impasses rather than Sci-Fi scenarios are needed. Dominance of such high-tech fantasies could crowd out socially and culturally relevant messages that mobile technologies have to offer.

2) The economic critique: Against the prevalent corporate position that considers the development and application of mobile information and communication technologies (ICTs) primarily in terms of economic growth, productivity gains, and organizational efficiency, we believe it is possible to articulate an approach that sheds light on the complex relations between technology, information, and power. We do not suggest that the profit principle should be rejected and replaced by one more concerned with the social, cultural, and even humanitarian promises of mobile ICTs. We simply argue for the inclusion of these greater issues into corporate efforts, e.g., in the form of new and additional metrics for technological research, development, marketing, and success parameters. Indeed, the two positions which could be dubbed the economic promise and the social-cultural promise of mobile technologies - are not mutually exclusive.

3) The political critique: Finally, we believe that the newest incarnation of the "Information Revolution" - what we call the "Anytime-Anywhere Economy" - is inadequately conceived as purely a quest for technological innovation and progress. Instead, what should guide the discussion about promises of new information and communication technologies is their 
potential to address differential and often unequal access to, and control over, information

resources (Robins \& Webster, 1999). Once recast in this way, the question of the promise of new ICTs necessarily transcends the technological realm and becomes a matter of management and control of information. Questions that need exploring include: Who will be able to communicate with whom and to what ends? More importantly, who will be excluded from communication and to what effect?

\section{REFERENCES}

Baudrillard, Jean (1997), Fragments: Cool Memories III, 1990-1995, translated by Emily Agar. London and New York: Verso.

Castells, M. (2001). The Internet Galaxy: Reflections on the Internet, business, and society. Oxford and New York: Oxford University Press.

Dholakia, Nikhilesh and Detlev Zwick (2001), "Privacy and Consumer Agency in the Information Age: Between Prying Profilers and Preening Webcams", Journal of Research for the Consumer, Vol. 1, No. 1, 2001. http://www.jrconsumers.com/

Dholakia, Nikhilesh and Nir Kshetri (2001), "Will M-Commerce Bridge the Global Digital Divide?" Working Paper, Kingston, RI: Research Institute for Telecommunications and Information Marketing (RITIM).

Drucker, P. F. (1970). Technology, management \& society; essays ( [1st ] ed.). New York,: Harper \& Row.

Drucker, P. F. (1985). Innovation and entrepreneurship : practice and principles ( 1st ed.). New York: Harper \& Row.

du Gay, P. (1997). Circulating Culture, Production of Culture/Cultures of Production. London: Sage.

Gates, B., Myhrvold, N., \& Rinearson, P. (1995). The Road Ahead [xiv, 286 p.]. New York: Viking.

Godin, B. (1997). The Rhetoric of a Health Technology: The Microprocessor Patient Card. Social Studies of Science, 27(6), 865-902.

Grint, K., \& Woolgar, S. (1995). On Some Failures of Nerve in Constructivist and Feminist Analyses of Technology. Science, Technology, \& Human Values, 20(3), 286- 
310.

Heidegger, M. (1977). The Question Concerning Technology. New York: Harper Colophon Books.

Hughes, T. P. (1986). The Seamless Web: Technology, Science, ecetera, ecetera. Social Studies of Science, 16, 281-292.

Huyssen, A. (1986). After the Great Divide: Modernism, Mass Culture, Postmodernism. Bloomington: Indiana University Press.

Kline, R., \& Pinch, T. (1996). Users as Agents of Technological Change: The Social Construction of the Automobile in the Rural United States. Technology and Culture, 37(4), 763-795.

Kline, R. R. (2000). Consumers in the country: Technology and social change in rural America. Baltimore, Md.: Johns Hopkins University Press.

Latour, B. (1987). Science in action: How to follow scientists and engineers through society. Cambridge, Mass.: Harvard University Press.

Latour, B., \& Woolgar, S. (1979). Laboratory life: The social construction of scientific facts. Beverly Hills: Sage Publications.

Lury, C. (1996). Consumer Culture. Oxford, England: Blackwell Publishers Ltd.

Mackay, H., \& Gillespie, G. (1992). Extending the Social Shaping of Technology Approach: Ideology and Appropriation. Social Studies of Science, 22(4), 685-716.

MacKenzie, D. A., \& Wajcman, J. (1985). The Social shaping of technology : how the refrigerator got its hum. Milton Keynes ; Philadelphia: Open University Press.

Nye, D. E. (1997). Narratives and Spaces: Technology and the construction of American culture. New York: Columbia University Press.

Palen, L. (2002). Mobile Telephony in a Connected Life. Communications of the ACM, 45(3), 78-82.

Pinch, T. J., \& Bijker, W. E. (1984). The Social Construction of Facts and Artefacts: Or How the Sociology of Science and the Sociology of Technology Might Benefit Each Other. Social Studies of Science, 14(3), 399-441.

Robins, K., \& Webster, F. (1999). Times of the Technoculture. London and New York: Routledge.

Rosen, P. (1993). The Social Construction of Mountain Bikes: Technology and Postmodernity in the Cycle Industry. Social Studies of Science, 23(3), 479-513. 
Rutsky, R. L. (1993). The Mediation of Technology and Gender: Metropolis, Nazism, Modernism. New German Critique, 60(Autumn), 3-32.

Rutsky, R. L. (1999). High Techne: Art and technology from the machine aesthetic to the posthuman. Minneapolis: University of Minnesota Press.

Schroeder, J. (2002). Visual Consumption. London and New York: Routledge.

Thompson, C. J., Locander, W. B., \& Pollio, H. R. (1990). The Lived Meaning of Free Choice: An Existential-Phenomenological Description of Everyday Consumer Experiences of Contemporary Married Women. Journal of Consumer Research, 17(3), 346-361.

Thyfault, M. E. (2001, March 26). Global Opportunities. InformationWeek, 65-66. Virilio, Paul (1986), Speed and Politics: An Essay on Dromology, translated by Mark Polizzotti. New York: Columbia University - Foreign Agent Series. Virilio, Paul (1995), The Art of the Motor, translated by Julie Rose. Minneapolis: University of Minnesota Press.

Virilio, Paul (2000), The Information Bomb, translated by Chris Turner. London and New York : Verso.

Webster, F. (1995). Theories of the Information Society. London and New York:

Routledge.

WWRF (2002). Book of Visions 2001. Wireless World Research Forum.

[1] Pinch and Bijker (1984) in their original article demonstrate how the development of the bicycle at the end of the $19^{\text {th }}$ century was chiefly driven by the competing concepts (in particular what was considered a problem) of relevant social groups (RSGs) such as women, old men, engineers, medical doctors, politicians, marketers, and others. For example, a technological capability like the air tire was initially cast as a solution to vibration of the low bicycle frame. But besides women, no other relevant group saw vibration as a real problem and the air tire did not gain any steam for a long time. Not until the air tire was mounted on a racing bicycle and proved superior in speed did it gain a foothold in the development path of the bicycle. However, for the air tire to become successful its meaning had to change from a solution to vibration to one of "speed". At this moment, with respect to two important social groups, the sporting cyclists and the general public, closure had been reached (Pinch and Bijker, 1984).

[2] Themes should really be viewed as responses to a constructed problem. For example, the theme "empowerment" could be seen as addressing the problem of feeling out of control or out of touch with loved ones (cf. (Thompson, Locander, \& Pollio, 1990)

[3] As Grint and Woolgar (1995) would argue, such a use of language suggests another kind of technological determinism. 